\title{
Evaluation of Clinical Relevance of Drug-Drug Interaction Alerts Prior to Implementation
}
S. M. M. Meslin 1,2,3
W. Y. Zheng ${ }^{4}$
R. O. Day ${ }^{1,2}$
E. M. Y. Tay ${ }^{1}$
M. T. Baysari 2,4

1 Department of Clinical Pharmacology and Toxicology, St Vincent's Hospital, University of New South Wales, Sydney, New South Wales, Australia

2 St Vincent's Clinical School, UNSW Medicine, University of New South Wales, Sydney, New South Wales, Australia

${ }^{3}$ School of Medical Sciences, University of New South Wales, Sydney, New South Wales, Australia

${ }^{4}$ Centre for Health Systems and Safety Research, Australian Institute of Health Innovation, Macquarie University, Sydney, New South Wales, Australia

\author{
Address for correspondence Sylvain Meslin, BMedSc(Hons), \\ St Vincent's Clinical School, University of New South Wales, \\ St Vincent's Hospital, Sydney, Australia 2010 \\ (e-mail: z3463953@unsw.edu.au).
}

Appl Clin Inform 2018;9:849-855.

Abstract

Keywords

- medical order entry systems

- drug interactions

- alert fatigue

- alert systems

- clinical decision support
Introduction Drug-drug interaction (DDI) alerts are often implemented in the hospital computerized provider order entry (CPOE) systems with limited evaluation. This increases the risk of prescribers experiencing too many irrelevant alerts, resulting in alert fatigue. In this study, we aimed to evaluate clinical relevance of alerts prior to implementation in CPOE using two common approaches: compendia and expert panel review.

Methods After generating a list of hypothetical DDI alerts, that is, alerts that would have been triggered if DDI alerts were operational in the CPOE, we calculated the agreement between multiple drug interaction compendia with regards to the severity of these alerts. A subset of DDI alerts $(n=13)$, with associated patient information, were presented to an expert panel to reach a consensus on whether each alert should be included in the CPOE.

Results There was poor agreement between compendia in their classifications of DDI severity (Krippendorff's $\alpha$ : 0.03 ; $95 \%$ confidence interval: -0.07 to 0.14 ). Only $10 \%$ of DDI alerts were classed as severe by all compendia. On the other hand, the panel reached consensus on 12 of the 13 alerts that were presented to them regarding whether they should be included in the CPOE.

Conclusion Using an expert panel and allowing them to discuss their views openly likely resulted in high agreement on what alerts should be included in a CPOE system. Presenting alerts in the context of patient cases allowed panelists to identify the conditions under which alerts were clinically relevant. The poor agreement between compendia suggests that this methodology may not be ideal for the evaluation of DDI alerts. Performing preimplementation review of DDI alerts before they are enabled provides an opportunity to minimize the risk of alert fatigue before prescribers are exposed to false-positive alerts. received

July 17,2018

accepted after revision

October 12, 2018 (c) 2018 Georg Thieme Verlag KG Stuttgart · New York
DOI https://doi.org/

$10.1055 / \mathrm{s}-0038-1676039$.

ISSN 1869-0327. 


\section{Background and Significance}

Drug-drug interactions (DDIs) are an important cause of preventable morbidity and mortality in the hospital setting. ${ }^{1}$ A DDI occurs when medications that are taken concurrently interfere with the anticipated effect of one another, potentially resulting in an adverse drug event. ${ }^{2,3}$ To minimize the risk of DDI-related adverse drug events in hospital patients, DDI alerts are embedded into computerized provider order entry (CPOE) systems. ${ }^{4}$

There is limited research demonstrating that DDI alerts are effective in reducing DDIs and subsequent patient harm. ${ }^{5} \mathrm{~A}$ persistent and widespread problem appears to be that DDI alerts are frequently ignored and overridden by prescribers. ${ }^{6-8}$ This is likely due to the large number of false-positive DDI alerts presented to prescribers, resulting in alert fatigue. Research has shown that prescribers could experience between 20 and 145 DDI alerts per 1,000 prescriptions, ${ }^{9,10}$ and that even 20 DDI alerts per 1,000 medication orders can result in alert fatigue. ${ }^{10}$ Thus, reducing the quantity of alerts alone is not sufficient to ensure alerts are read and acted upon. The clinical relevance of alert information should also be evaluated to help guide alert inclusion.

To determine which alerts to include and exclude in CPOE requires evaluation of their clinical relevance. Typically, this involves a review of alerts which are frequently overridden by users. ${ }^{11}$ Alerts that rarely result in a medication order being changed are viewed to be of limited value. However, this methodology requires DDI alerts to be operational in a CPOE before being evaluated.

Interestingly, evaluation of DDI alerts is rarely done prior to implementation in a system. ${ }^{12,13}$ Instead, DDI alerts, often part of the "out-of-the-box" vendor functionality of CPOE, are implemented to meet Meaningful use or accreditation requirements. ${ }^{14,15}$ However, evaluation and the subsequent removal of low-quality alerts following implementation of DDI alerts has been shown to be a complex and challenging task. ${ }^{11,16,17}$ For example, in one study, frequently overridden DDI alerts were reviewed by an expert panel, but the panel could not agree that any of the 86 DDI alerts identified should be removed from the system. ${ }^{11}$

Two approaches available to organizations wishing to evaluate their alerts prior to implementation in a CPOE are drug compendia and expert panel review. A common approach involves comparing the agreement between multiple drug interaction compendia on the severity of detected interactions. $^{18,19}$ High agreement between compendia, regarding the severity of DDI alerts, could indicate that the alert is clinically relevant. ${ }^{18,19}$

In other studies, clinical experts have been tasked with reviewing alerts, with the aim of excluding irrelevant alerts from the system. ${ }^{20,21}$ However, this approach is sometimes problematic, as poor agreement between panelists regarding the clinical relevance of alerts has been found. ${ }^{11,17,22,23}$ This may be because panelists are often required to rate alerts independently, with no opportunity to discuss their decisions, and alerts are often presented in the absence of the clinical context in which they are triggered, possibly making it difficult for panelists to conceptualize clinical relevance. In previous studies, panelists have been required to indicate whether an alert is relevant or not, and rarely given the opportunity to identify the contexts in which they believe a specific DDI alert to be clinically relevant. ${ }^{11}$ Only triggering DDI alerts in the presence of particular context factors has been suggested as a method of reducing false-positive alerts. ${ }^{24}$ For example, if a particular DDI is harmful in newborns but not adults, such as the coadministration of ceftriaxone and calcium, then the patient's age is a context factor that could be used to dictate whether to trigger the DDI alert. ${ }^{24}$

At our study hospital, a decision was made to evaluate DDI alerts prior to implementation in a CPOE. An audit of "hypothetical" DDI alert numbers revealed that DDI alert rate would be high (147 DDI alerts per 1,000 medication orders) and would likely contribute to the development of alert fatigue. Thus, this provided a strong rationale to evaluate DDI alert quality in terms of clinical relevance before implementation into a CPOE.

\section{Objective}

The objective of this study was to trial two commonly used methods (compendia review and an expert panel) to assess clinical relevance of DDI alerts before implementation. The results of the study would inform which DDI alerts to implement and under what context factors they should trigger.

\section{Methods}

\section{Study Setting}

This study was conducted in a 379-bed public teaching hospital in Australia. The hospital uses the CPOE MedChart (referred to herein as MedChart). MedChart allows electronic prescribing, review, and administration of medications. ${ }^{25}$ Several computerized alerts are operational in the system including allergy alerts, therapeutic duplication alerts, and local messages (e.g., reminders about antibiotic restrictions). At the time of the study, DDI alerts were not enabled.

This study was approved by the hospital's human research ethics committee.

Identification of DDI Alerts for Testing Clinical Relevance To generate DDI alerts, medications for a sample of patients ( $n=78$ ) were entered into MedChart's training environment and all hypothetical DDI alerts were noted. The sample consisted of all patients that were discharged over two consecutive days. The patients were from seven specialties including: neurology, gastroenterology, infectious diseases, geriatrics, oncology, cardiology, and cardiothoracic surgery.

The DDI compendium utilized by MedChart is MIMS, and as the hospital planned to implement only DDI alerts of the highest severity, only severe DDI alerts were subsequently assessed for quality. ${ }^{26}$ In MIMS, severe DDI alerts warn against interactions between medications that may be lifethreatening or cause permanent damage. ${ }^{26}$ 


\section{Assessing Quality of DDI Alerts Using Compendia}

The severe DDI alerts were entered into three other drug interaction compendia: Stockley's Drug Interactions, Micromedex, and YouScript. These compendia were selected based on high usage and reputation. ${ }^{9,27-29}$

The severity rating of each drug pair that triggered a DDI alert was reviewed in the three compendia (see - Appendix A). Agreement between the three compendia and MIMS was assessed using Krippendorff's $\alpha$. An $\alpha$ of 1 indicates perfect agreement between compendia, a value of 0 no agreement, and a value of -1 indicates an inverse agreement between compendia. ${ }^{30}$ IBM SPSS Statistics Version 23 was used for analysis.

\section{Assessing Quality of DDI Alerts Using an Expert Panel}

The panel consisted of five health care professionals: two clinical pharmacologists, two senior clinical pharmacists, and one geriatrician. Six patient cases were randomly selected and presented to the panel. These cases would have triggered 13 different hypothetical severe DDI alerts if enabled in a CPOE. Short case presentations were delivered to the panel, including information on medical history and progress during admission.

Panel members were asked to review the patient's medication charts and were provided with supporting information including: the relevant hypothetical DDI alert, how frequently the alert would fire in our sample of 78 patients if enabled, the literature summaries from the four compendia, as well as the alerts severity rankings from each compendium. For each of the DDI alerts, panelists individually decided whether the alert should be included in MedChart. Then, all panelists presented their independent view as a prelude to a general open discussion. During the discussion, the panelists explained how and why they determined whether an alert should or should not be included in a CPOE and attempted to form a consensus. The panel was encouraged to discuss context factors that related to the patient (i.e., age), the medications (i.e., dose and route of administration), and the organization (i.e., whether the prescriber was a junior medical officer). Consensus was defined as a minimum of four of the five panelists reaching agreement, after open discussion. Panelists were informed that it was not necessary for a consensus opinion to be reached.

\section{Results}

\section{Alert Quality Using Compendia}

A total of 147 DDI alerts were triggered by 45 unique DDI drug pairs in the 78 hospital patients. These 45 drug pairs were entered into Stockley's Drug Interactions, Micromedex, and YouScript. In total, 8 of the 45 unique drug pairs (18\%) were ranked as severe in all four compendia. These 8 drug pairs accounted for 15 of the 147 (10\%) alerts. Statistical analysis confirmed that there was poor agreement between drug compendia on the severity classification of DDIs. The Krippendorff's $\alpha$ was 0.03 with a $95 \%$ confidence interval of 0.07 to 0.14 .

The six drug pairs that would have triggered the highest number of DDI alerts, using the MIMS interaction module, are shown in -Table 1. Oxycodone and oxycodone/naloxone was
Table 1 Top six drug pairs resulting in DDI alerts

\begin{tabular}{|l|l|l|}
\hline Drug pair & $\begin{array}{l}\text { Number of } \\
\text { DDI alerts } \\
\text { triggered } \\
\text { (\% of total) }\end{array}$ & $\begin{array}{l}\text { Compendia } \\
\text { that ranked } \\
\text { DDI as severe }\end{array}$ \\
\hline $\begin{array}{l}\text { Oxycodone and } \\
\text { naloxone/oxycodone }\end{array}$ & $13(9)$ & $1 / 4$ \\
\hline $\begin{array}{l}\text { Amiodarone and } \\
\text { furosemide }\end{array}$ & $10(7)$ & $2 / 4$ \\
\hline $\begin{array}{l}\text { Amiodarone and } \\
\text { tacrolimus }\end{array}$ & $9(6)$ & $3 / 4$ \\
\hline $\begin{array}{l}\text { Morphine and } \\
\text { naloxone/oxycodone }\end{array}$ & $9(6)$ & $3 / 4$ \\
\hline $\begin{array}{l}\text { Itraconazole and } \\
\text { tacrolimus }\end{array}$ & $7(5)$ & $3 / 4$ \\
\hline $\begin{array}{l}\text { Amiodarone and } \\
\text { warfarin }\end{array}$ & $7(5)$ & $2 / 4$ \\
\hline
\end{tabular}

Abbreviation: DDI, drug-drug interaction.

the drug pair that triggered the most alerts in our sample, but this interaction was only classed as a severe DDI by MIMS.

\section{Alert Quality Using an Expert Panel}

The panelists reached consensus after open discussion on 12 of the 13 alerts triggered in the patient cases ( - Table 2 ). Nine were recommended for inclusion in the system, but for four, it was suggested that these should trigger only in certain clinical contexts. These context factors are shown in -Table 2 .

\section{Discussion}

This study used two common methods to evaluate the clinical relevance of DDI alerts before implementation into a CPOE. In assessing the quality of alerts using compendia, only a small number of hypothetical alerts (10\%) were classed as severe by all four compendia. The very poor agreement found between compendia with respect to classifications of severity, brings into question the usefulness of compendia alone to determine which alerts should be included or excluded in a CPOE. This poor agreement between compendia is echoed in other stu$\operatorname{dies}^{18,31,32}$ and is due to different, nontransparent DDI prediction models used to classify the severity of interactions. ${ }^{20}$ The poor agreement is concerning, as it is common for prescribers to only consult one compendium when reviewing risk of adverse drug events.

When a subset of DDI alerts were presented to an expert panel in the context of individual patient cases and panelists were given the opportunity to discuss their views, we found high agreement between panelists with respect to whether alerts should be included in a CPOE. Of the 13 alerts presented, panelists reached a consensus on 12 of the alerts. Panelists agreed that three should be excluded and four included only in certain contexts. Previous studies have reported moderate to poor agreement between panelists when determining the importance of DDI alerts. ${ }^{11,22,23}$ The high agreement observed in our study could be attributed to 
Table 2 Findings from the expert panel

\begin{tabular}{|c|c|c|}
\hline Drug pair & $\begin{array}{l}\text { Panel's response } \\
\text { after open } \\
\text { discussion }\end{array}$ & Key context factors identified \\
\hline Furosemide and gentamicin & Include & \\
\hline Amiodarone and domperidone & Include & \\
\hline Amiodarone and warfarin & Include & \\
\hline Ondansetron and domperidone & Include & \\
\hline Amiodarone and ondansetron & Include & \\
\hline Heparin and salicylates & $\begin{array}{l}\text { Include in certain } \\
\text { clinical contexts }\end{array}$ & $\begin{array}{l}\text { - IF patient is older than } 66 \text { y old THEN trigger } \\
\text { - IF renally impaired THEN trigger } \\
\text { - IF hyperkalemic THEN trigger }\end{array}$ \\
\hline Methadone and ondansetron & $\begin{array}{l}\text { Include in certain } \\
\text { clinical contexts }\end{array}$ & $\begin{array}{l}\text { - IF no ECG performed THEN trigger } \\
\text { - IF dose (ondansetron) > } 16 \mathrm{mg} \text { THEN trigger } \\
\text { - IF dose (methadone) }>80 \mathrm{mg} \text { THEN trigger } \\
\text { - IF route of ondansetron is parenteral THEN trigger }\end{array}$ \\
\hline Enoxaparin and warfarin & $\begin{array}{l}\text { Include in certain } \\
\text { clinical contexts }\end{array}$ & $\begin{array}{l}\text { - IF INR is elevated THEN trigger } \\
\text { - IF junior medical officer prescribing THEN trigger } \\
\text { - IF renal impairment THEN trigger }\end{array}$ \\
\hline Temazepam and olanzapine & $\begin{array}{l}\text { Include in certain } \\
\text { clinical contexts }\end{array}$ & $\begin{array}{l}\text { - IF patient is older than } 75 \text { THEN trigger; } \\
\text { - IF more than } 5 \text { h between administrations THEN do not trigger } \\
\text { - IF STAT dose THEN do not trigger }\end{array}$ \\
\hline Lorazepam and olanzapine & No consensus & \\
\hline Amiodarone and bisoprolol & Exclude & - The alert is warning for the desired effect (i.e., bradycardia) \\
\hline $\begin{array}{l}\text { Aspirin and selective } \\
\text { serotonin receptor inhibitors }\end{array}$ & Exclude & $\begin{array}{l}\text { - Well-known DDI with likely low significance in the average person } \\
\text { - Common combination that is taken without adverse drug events }\end{array}$ \\
\hline Ramipril and spironolactone & Exclude & - Indications outweigh the risks of DDI \\
\hline
\end{tabular}

Abbreviations: DDI, drug-drug Interaction; ECG, electrocardiogram; INR, international normalized ratio.

the methodology adopted, which differed from the approach taken in other studies. ${ }^{22,23}$ First, the panelists were encouraged to openly discuss the reasoning for their recommendations, while other studies have utilized an independent and noncollaborative approach to the assessment of alert relevance. $^{22,23}$ Second, alerts in this study were presented in the context of particular patient cases. Consideration of the patient and their clinical context is a crucial element in determining clinical relevance. The panel members were able to consider the context factors impacting on the probability DDI resulting in an adverse effect. ${ }^{24}$ For example, the panel agreed that the increased risk of bleeding due to the coadministration of enoxaparin and warfarin was only clinically relevant when the patient's international normalized ratio (INR) (a laboratory indicator for bleeding risk) was elevated. Incorporating INR information into the alerting system would ensure that when triggered, the DDI alert would be relevant to the prescriber's decision.

Research has shown that only triggering alerts in the presence of relevant context factors could reduce overall alert burden significantly. ${ }^{24}$ Our current evaluation demonstrates that presenting alerts in conjunction with patient context and allowing for open discussion, not only facilitated agreement between panelists on clinical relevance of DDI alerts but allowed the identification of context factors for improving alert specificity.
This study had several limitations. The expert panel was limited by time and was only able to review a sample of 13 alerts that triggered in 6 patient cases. Level of experience, profession, and expertise of panel members may have impacted results; however, we attempted to minimize these influences by including a range of different professionals (i.e., pharmacists, clinical pharmacologists, and geriatricians) and providing each panelist with an opportunity to share their view. Finally, we reassured the panelists that reaching a consensus was not necessary.

Although utilizing an expert panel is more resourceintensive and time-consuming than inputting medications into compendia and reviewing agreement, we suggest presenting a large sample of alerts to the expert panel before implementation. This would ensure that alerts likely to cause the highest burden to prescribers are clinically relevant. An evaluation of alert burden and alert relevance postimplementation would reinforce the effectiveness of this approach to minimize the risk of alert fatigue.

\section{Conclusion}

In this study, we assessed the clinical relevance of DDI alerts in terms of clinical relevance prior to their implementation in a CPOE. We found drug compendia to be unreliable in their classification of DDI alerts, but the expert panel was 
highly consistent in their assessments of clinical relevance and in their identification of context factors, most likely because alerts were presented in the context of specific patient cases, and experts were permitted to share their clinical knowledge and discuss any differences in opinion. Although more resource-intensive, we recommend expert panel review as an effective approach for assessing clinical relevance of DDI alerts prior to alert implementation, to minimize the risk of alert fatigue before prescribers are exposed to alerts.

\section{Clinical Relevance Statement}

Hospitals across the world are utilizing CPOE systems and, commonly, enable extra functionalities such as drug-drug interaction alerts. However, due to overexposure, alert fatigue is a common problem. This article identifies a method that may reduce alert rate by improving clinical relevance of alerts before they are implemented in a CPOE.

\section{Multiple Choice Question}

What did this study do differently, that potentially resulted in panelists having higher agreement on whether DDI alerts should be included or excluded from the CPOE?

a. Blinded the panelists to each other's answers to keep views unbiased.

b. Blinded the panelists to the clinical context of the patient to ensure that the results were generalizable.

c. Allowed the panelists to discuss their reasoning openly with each other with respect to the clinical relevance and important context factors with each DDI alert.

d. Used only panelists from one specialty so that they would reach consensus.

Correct Answer: The correct answer is option c. Allowing for open discussion gave way to fruitful debate between the panelists and was successful at helping them come to agreement on 12 of the 13 DDI alerts they reviewed.

Protection of Human and Animal Subjects

Ethics approval was obtained by the local hospital's ethics board.

\section{Funding}

This study was funded by National Health and Medical Research Council Program Grant APP1054146.

\section{Conflict of Interest}

None.

\section{Acknowledgments}

We would like to acknowledge the funding (National Health and Medical Research Council Program Grant APP1054146), Leone Snowden from NSW Medicines Information Centre, and the panel members.

\section{References}

1 Day RO, Snowden L, McLachlan AJ. Life-threatening drug interactions: what the physician needs to know. Intern Med J 2017;47 (05):501-512

2 Magro L, Moretti U, Leone R. Epidemiology and characteristics of adverse drug reactions caused by drug-drug interactions. Expert Opin Drug Saf 2012;11(01):83-94

3 Schachter M. The epidemiology of medication errors: how many, how serious? Br J Clin Pharmacol 2009;67(06):621-623

4 Beeler PE, Bates DW, Hug BL. Clinical decision support systems. Swiss Med Wkly 2014;144:w14073

5 Zheng WY, Richardson LC, Li L, Day RO, Westbrook JI, Baysari MT. Drug-drug interactions and their harmful effects in hospitalised patients: a systematic review and meta-analysis. Eur J Clin Pharmacol 2018;74(01):15-27

6 Peterson JF, Bates DW. Preventable medication errors: identifying and eliminating serious drug interactions. J Am Pharm Assoc (Wash) 2001;41(02):159-160

7 Slight SP, Seger DL, Nanji KC, et al. Are we heeding the warning signs? Examining providers' overrides of computerized drug-drug interaction alerts in primary care. PLoS One 2013;8(12):e85071

8 van der Sijs H, Aarts J, Vulto A, Berg M. Overriding of drug safety alerts in computerized physician order entry. J Am Med Inform Assoc 2006;13(02):138-147

9 Fung KW, Kapusnik-Uner J, Cunningham J, Higby-Baker S, Bodenreider O. Comparison of three commercial knowledge bases for detection of drug-drug interactions in clinical decision support. J Am Med Inform Assoc 2017;24(04):806-812

10 Payne TH, Nichol WP, Hoey P, et al. Characteristics and override rates of order checks in a practitioner order entry system. Proceedings of AMIA Symposium; 2002:602-606

11 van der Sijs H, Aarts J, van Gelder T, Berg M, Vulto A. Turning off frequently overridden drug alerts: limited opportunities for doing it safely. J Am Med Inform Assoc 2008;15(04):439-448

12 Paterno MD, Maviglia SM, Gorman PN, et al. Tiering drug-drug interaction alerts by severity increases compliance rates. J Am Med Inform Assoc 2009;16(01):40-46

13 Beccaro MAD, Villanueva R, Knudson KM, Harvey EM, Langle JM, Paul W. Decision support alerts for medication ordering in a computerized provider order entry (CPOE) system: a systematic approach to decrease alerts. Appl Clin Inform 2010;1(03): 346-362

14 HiMSS Analytics. Electronic Medical Record Adoption Model; 2017. Available at: https://www.himssanalytics.org/emram. Accessed October 31, 2018

15 Medicare and Medicaid Services. Electronic Health Record Incentive Program: Centers for Medicare and Medicaid Services; 2010. Available at: https://www.federalregister.gov/documents/2010/ 07/28/2010-17207/medicare-and-medicaid-programs-electronic-health-record-incentive-program. Accessed October 31, 2018

16 Bryant AD, Fletcher GS, Payne TH. Drug interaction alert override rates in the Meaningful Use era: no evidence of progress. Appl Clin Inform 2014;5(03):802-813

17 Baysari MT, Westbrook JI, Egan B, Day RO. Identification of strategies to reduce computerized alerts in an electronic prescribing system using a Delphi approach. Stud Health Technol Inform 2013;192:8-12

18 Abarca J, Malone DC, Armstrong EP, et al. Concordance of severity ratings provided in four drug interaction compendia. J Am Pharm Assoc (2003) 2004;44(02):136-141

19 van Leeuwen RW, Jansman FG, van den Bemt PM, et al. Drug-drug interactions in patients treated for cancer: a prospective study on clinical interventions. Ann Oncol 2015;26(05):992-997

20 Scheife RT, Hines LE, Boyce RD, et al. Consensus recommendations for systematic evaluation of drug-drug interaction evidence for clinical decision support. Drug Saf 2015;38(02):197-206 
21 Phansalkar S, van der Sijs H, Tucker AD, et al. Drug-drug interactions that should be non-interruptive in order to reduce alert fatigue in electronic health records. J Am Med Inform Assoc 2013; 20(03):489-493

22 Strasberg HR, Chan A, Sklar SJ. Inter-Rater Agreement among Physicians on the Clinical Significance of Drug-Drug Interactions. AMIA Annual Symposium Proceedings. 2013 11/16;2013:1325-1328

23 Smithburger PL, Kane-Gill SL, Benedict NJ, Falcione BA, Seybert AL. Grading the severity of drug-drug interactions in the intensive care unit: a comparison between clinician assessment and proprietary database severity rankings. Ann Pharmacother 2010;44 (11):1718-1724

24 Seidling HM, Klein U, Schaier M, et al. What, if all alerts were specific-estimating the potential impact on drug interaction alert burden. Int J Med Inform 2014;83(04):285-291

25 MedChart. MedChart Electronic Medication Management: DXC. technology; 2017. Available at: http://www.dxc.technology/providers/offerings/139499/140202-medchart_electronic_medication_management. Accessed October 31, 2018

26 MIMS. Decision Support Overview. Available at: http://www.mims. com.au/index.php/products/emims2017. Accessed June 5, 2017
27 Vonbach P, Dubied A, Krähenbühl S, Beer JH. Evaluation of frequently used drug interaction screening programs. Pharm World Sci 2008;30(04):367-374

28 Muhič N, Mrhar A, Brvar M. Comparative analysis of three drugdrug interaction screening systems against probable clinically relevant drug-drug interactions: a prospective cohort study. Eur J Clin Pharmacol 2017;73(07):875-882

29 Reis AMM, Cassiani SHDB. Evaluation of three brands of drug interaction software for use in intensive care units. Pharm World Sci 2010;32(06):822-828

30 Hayes AF, Krippendorff $\mathrm{K}$. Answering the call for a standard reliability measure for coding data. Commun Methods Meas 2007;1(01):77-89

31 Conde-Estévez D, Echeverría-Esnal D, Tusquets I, Albanell J. Potential clinical relevant drug-drug interactions: comparison between different compendia, do we have a validated method? Ann Oncol 2015;26(06):1272-1272

32 Saverno KR, Hines LE, Warholak TL, et al. Ability of pharmacy clinical decision-support software to alert users about clinically important drug-drug interactions. J Am Med Inform Assoc 2011; 18(01):32-37 
Appendix A Severity ratings from multiple drug compendia

\begin{tabular}{|c|c|c|c|c|}
\hline $\begin{array}{l}\text { Comparative } \\
\text { ranking }\end{array}$ & $\begin{array}{l}\text { MIMS drug interaction } \\
\text { checker }\end{array}$ & Micromedex & YouScript & Stockley's Drug Interactions \\
\hline \multirow[t]{2}{*}{ SEVERE } & \multirow[t]{2}{*}{$\begin{array}{l}\text { Severe: The interaction } \\
\text { between these medica- } \\
\text { tions may be life-threa- } \\
\text { tening or may cause } \\
\text { permanent damage. } \\
\text { These medications are } \\
\text { not usually used con- } \\
\text { currently; medical } \\
\text { intervention may be } \\
\text { required }\end{array}$} & $\begin{array}{l}\text { Contraindicated: Drug } \\
\text { pairs are contraindi- } \\
\text { cated for concurrent } \\
\text { use }\end{array}$ & $\begin{array}{l}\text { Contraindication: This } \\
\text { drug has an interaction } \\
\text { that is contraindicated } \\
\text { in the product insert } \\
\text { due to the potential for } \\
\text { a severe or life-threa- } \\
\text { tening reaction. This } \\
\text { combination should not } \\
\text { be administered } \\
\text { together }\end{array}$ & \multirow[t]{2}{*}{$\begin{array}{l}\text { Severe: Interactions that } \\
\text { may totally incapacitate a } \\
\text { patient or result in perma- } \\
\text { nent detrimental effect. Can } \\
\text { be life-threatening }\end{array}$} \\
\hline & & $\begin{array}{l}\text { Major: Potentially life- } \\
\text { threatening interac- } \\
\text { tions and/or require } \\
\text { medical intervention to } \\
\text { minimize serious } \\
\text { adverse effects }\end{array}$ & $\begin{array}{l}\text { Major Clinical Impact: } \\
\text { This drug has an inter- } \\
\text { action that may result in } \\
\text { severe clinical effects or } \\
\text { large changes in drug } \\
\text { levels. The risks of the } \\
\text { interaction generally } \\
\text { outweigh the benefits } \\
\text { of prescribing the drug }\end{array}$ & \\
\hline MODERATE & $\begin{array}{l}\text { Moderate: These medi- } \\
\text { cations may interact } \\
\text { resulting in the poten- } \\
\text { tial deterioration of the } \\
\text { patient's condition. The } \\
\text { patient should be mon- } \\
\text { itored for the possible } \\
\text { manifestations of the } \\
\text { interaction. Medical } \\
\text { intervention or a } \\
\text { change in therapy may } \\
\text { be required }\end{array}$ & $\begin{array}{l}\text { Moderate: The interac- } \\
\text { tion may result in } \\
\text { exacerbation of the } \\
\text { patient's condition } \\
\text { and/or require an } \\
\text { alteration in therapy }\end{array}$ & $\begin{array}{l}\text { Moderate Clinical } \\
\text { Impact: This drug has } \\
\text { an interaction that may } \\
\text { result in substantial } \\
\text { clinical effects or mod- } \\
\text { erate changes in drug } \\
\text { levels. Changes in ther- } \\
\text { apy, such as making } \\
\text { dose adjustments or } \\
\text { prescribing alterna- } \\
\text { tives, may be warranted }\end{array}$ & $\begin{array}{l}\text { Moderate: For interactions } \\
\text { that could cause consider- } \\
\text { able distress or partial inca- } \\
\text { pacitation of patients. } \\
\text { Unlikely to be life- } \\
\text { threatening }\end{array}$ \\
\hline \multirow[t]{2}{*}{ MINOR } & $\begin{array}{l}\text { Minor: Clinical effects } \\
\text { of the interaction are } \\
\text { limited and may be } \\
\text { bothersome but would } \\
\text { not usually require a } \\
\text { major change to ther- } \\
\text { apy. The patient should } \\
\text { be monitored for the } \\
\text { possible manifestations } \\
\text { of the interaction }\end{array}$ & \multirow[t]{2}{*}{$\begin{array}{l}\text { Minor: The interaction } \\
\text { would have limited } \\
\text { clinical effects. Mani- } \\
\text { festations may include } \\
\text { an increase in the fre- } \\
\text { quency or severity of } \\
\text { the side effects but } \\
\text { generally would not } \\
\text { require a major altera- } \\
\text { tion in therapy }\end{array}$} & $\begin{array}{l}\text { Minor Clinical Impact: } \\
\text { This drug has an inter- } \\
\text { action that may result in } \\
\text { minor clinical effects or } \\
\text { small changes in drug } \\
\text { levels. The benefits of } \\
\text { prescribing the drug } \\
\text { generally outweigh the } \\
\text { risks of the interaction. } \\
\text { Major changes in ther- } \\
\text { apy are not expected, } \\
\text { although minor dose } \\
\text { adjustments may be } \\
\text { appropriate }\end{array}$ & \multirow[t]{2}{*}{$\begin{array}{l}\text { Mild: For interactions that } \\
\text { are unlikely to result in an } \\
\text { effect or that if an effect was } \\
\text { to occur it would be mild and } \\
\text { unlikely to incapacitate the } \\
\text { majority of patients }\end{array}$} \\
\hline & $\begin{array}{l}\text { Caution: The interac- } \\
\text { tion may occur based } \\
\text { on the mechanism of } \\
\text { action of the coadmi- } \\
\text { nistered medicines. Be } \\
\text { alert for increased or } \\
\text { decreased effect, } \\
\text { depending on the com- } \\
\text { bination of medicines }\end{array}$ & & $\begin{array}{l}\text { Minimal Clinical } \\
\text { Impact: This drug may } \\
\text { be associated with } \\
\text { clinically insignificant } \\
\text { and/or favorable inter- } \\
\text { actions. No change in } \\
\text { therapy is necessary }\end{array}$ & \\
\hline
\end{tabular}

Note: Compendia used nonstandardized severity terminology. This table shows how these inconsistent labels were grouped for comparison across compendia. 